\title{
Massively multiplayer online vs. tabletop role playing games. Is there a difference in "game addiction"?
}

\author{
Evmorfia Koukia* \\ Associate Professor in Psychiatric-Mental Health Nursing, School of Health Sciences, University of Athens, Greece
}

\begin{abstract}
Online game playing is experiencing rapid growth among population. Mental health professionals and research papers argue the fact of internet addiction and problematic use among players, especially in massively multiplayer online role-playing games (MMORPGs). This study aimed to investigate the differences between players of online role-playing games and players of tabletop (pen and paper) RPGs, to explore the addictive dynamic of RPGs and to delineate the possible underlying factors that affect addiction. Semi-structured interviews were conducted among 36 adults (former players). Eighteen (18) players of online role-playing games and eighteen (18) players of tabletop RPGs. Online players identified both positive and negative aspects alike. Tabletop players mentioned mainly positive effects. Analysis of data have shown that there is an addictive dynamic of the game when is played online.
\end{abstract}

\begin{abstract}
Abbreviations: Internet Gaming Disorder (IGD); DSM-5 (Diagnostic and Statistical Manual of Mental Disorder); Massive Multiplayer Online Role-Playing Games (MMORPGs); Role-Playing Game (RPG).
\end{abstract}

\section{Introduction}

Internet Gaming Disorder (IGD) has been included in section III of the DSM-5 (Diagnostic and Statistical Manual of Mental Disorder) and refers to the problematic use of computer games (both online and offline). A diagnosis of IGD is based on nine criteria and can be diagnosed if at least five of those are met in the last 12 months [1].

Several studies investigated the prevalence of IGD in adolescents and young adults. They reported associations with sociodemographic and psychopathological aspects. The majority of studies found high levels of internet addiction, especially in males of lower age. Players reported neglect in social life, and high levels of anxiety and depression [2]. Adolescents with IGD have shown lower self-perceived social support, more friends only known through the Internet, and a lower health-related quality of life compared with the group without IGD [3].

A review concerning Internet addiction and problematic internet use has found that there is a need for a consensus regarding diagnostic criteria and measures in order to improve reliability across studies and to develop effective and efficient treatment approaches for treatment seekers. All studies included had not considered the types of games that people used to play [4].

Additionally, internet and video games are extremely popular among young adults. In particular, fantasy games based on the Dungeons and Dragons role-playing game, which are called massive multiplayer online role-playing games (MMORPGs). MMORPGs are the most popular type of online game which allows gamers to create and continuously develop their own character through playing with other players across the globe, within a fantasy adventure context. There is a growing concern that this type of game has negative effects on players' lives and may contribute to the formation of an addictive behavior $[5,6]$. Given the fact that approximately $86 \%$ of Internet Addiction cases have another DSM-IV-TR diagnosis present, leads some to argue that the Internet in itself is not an issue, but rather the content, as in massive multiplayer online games (MMORPGs) [7,8].

Considering that the majority of studies referred to IGD, recognized that structural and motivational aspects of computer games, play an important role in the formation of internet addiction, this study will focus on the game itself and will value the views and thoughts of former players.

\section{Aims}

The aims of the study are:

1. To investigate the differences between players of online roleplaying games and players of pen and paper (or tabletop role-playing game) RPGs, perceptions.

2. To explore the addictive dynamic of RPGs.

3. To delineate the possible underlying factors that affect possible addiction.

\section{Method}

\section{Participants}

The sample consisted of two groups of 36 male former players. Group A: eighteen (18) players of online role-playing games and group B: Eighteen (18) players of tabletop role-playing game (or pen \& paper RPGs). All players have played at least 2 years as university students

${ }^{\star}$ Correspondence to: Evmorfia Koukia, Associate Professor in Psychiatric Nursing, School of Health Sciences, University of Athens, Greece, Tel: 0030210 7781174; FAX: 0030210 7718320; E-mail: ekoukia@nurs.uoa.gr

Key words: online games, tabletop fantasy games, internet addiction, problematic use

Received: January 08, 2018; Accepted: January 20, 2018; Published: January 22, 2018 
and had stopped playing in the time of the interview. All players had no record for psychiatric disorder or therapeutic interventions.

Group A. The 18 players were playing Dungeons and Dragons, a tabletop fantasy game played as a group (4-8 people) with a master of the game (Dungeon Master, DM) who actually constructs the setting, apply the rules, guide the players throughout a plot based on his narrative and frequently dices are rolled to judge the outcome of an encounter.

Players assume different roles and formulate different characters (like warriors, wizards, rogues, monks, priests) belonging to a wide range of races: dwarfs, elves, humans, halflings, orcs and even beings of celestial or demonic origin. This group of characters functions as a team in order to surpass the difficulties, tasks, riddles and encounters, the DM will pose and above all, they fight and try to exterminate the fictional monsters and non-player characters that the DM throws to them.

The game is actually lasting many hours. The DM interrupts the action most usually on a critical turn of events (a battle to be fought in the next minutes, a poison to act or a crucial decision to be made) and sets the next meeting (usually in the next week), keeping the players on edge, making them anticipate the next session.

Group B: The 18 players were playing mainly MMPORGS. The game is played online, through a browsing server, which shows only the action and usually some rough dialogue in written language. Players have to sit in front of a PC screen, a tablet or even a smartphone, and they also have to play unstoppably, since the plot is ever unravelling, even if they are offline. Most often, such servers require a fee from the players, for them to be able to enter the game, to start playing and most importantly to develop their character.

\section{Data collection}

\section{Procedure}

The type of sampling used was a combination of incidental and convenience sampling. Their educational background was mainly from a department of School of Health Sciences and they were initially contacted through Facebook. Participants were then approached by messenger and telephone and subsequently by email, in the process of which provisional consent was obtained, and they were provided with written explanation of the study aims. Assurances were given to players, concerning confidentiality and anonymity. Subjects have given their informed consent and that the study protocol has been approved by the institute's committee on human research.

Data was collected using a face-to-face semi-structured interview schedule. Interviews generally lasted a minimum of 1 hour. All interviews were tape-recorded.

We have chosen the semi-structured interviews which consisted of 5 key questions that help to define the areas to be explored and allows for the elaboration of information that is important to participants.

Players were asked to provide information concerning five (3) structured questions about:

1. Games' characteristics

2. Negative effect on players' lives

3. Positive effects

They also were called to answer to unstructured questions concerning:

\section{Possible causes for their behavior}

\section{Future intentions}

The unstructured nature of the interview allowed players to describe their experience with RPGs and give a possible explanation for their behavior.

\section{Data analysis}

Tape-recorded data were transcribed in full and subjected to qualitative thematic analysis. Thematic analysis emphasizes pinpointing, examining, and recording themes within data. It also allows psychological interpretation of data and generalization of the results. Data was coded in a variety of important themes. The reliability and the validity were ensured by the presence of a second independent researcher that confirmed the analysis of data.

\section{Results}

The sample of the present study comprised a total of 36 male former players. Eighteen (18) players of online role-playing games and group B: eighteen (18) players of tabletop RPGs with a mean age of 32.3 years $(\mathrm{SD}=5.2$ years; range $25-42$ years). All subjects were males. Five main themes emerged from the qualitative analysis of the interview transcripts:

1. Games' characteristics

2. Negative effect on players' lives

3. Positive effects

4. Possible causes for their behavior/possible explanations about addiction

\section{Future intentions}

\section{Theme: Games' characteristics}

\section{Online players}

Internet players have identified some characteristics of the game that contribute to its appealing nature: Amazing graphics, vivid colors, fast plot, unexpected scenario.

One player said:

Extract: "Living in a fantasy world is simply awesome!"

Choosing a character with certain characteristics provide the player the freedom to be someone else.

Extract: "I was feeling powerful. I could do whatever I wanted"

\section{Tabletop players}

Players noted that the main characteristic of the game was the character choice and the role-playing of the character. The main enjoyments of the game were the role-playing of the character, the collaborations within the team and the fictional adventure.

Extract: "Team had the control of the game. If I had to be absent someone else was playing my character and I had an agony not to die!"

Gaming sessions last for many hours. It is rather a gathering of friends.

Extract: "All week I was thinking of the Saturday gathering. I remember that once my character was hurt in a battle and I was anxious to see what will happen in our next meeting. We had a great time!" 
A player identified that the game requires being creative and imaginative.

Extract: "You have to imagine the next step, prevent the damage and cooperate with others to escape danger"

\section{Theme: Negative effect on players' lives}

Online players

Players said that they were playing almost all day long in their student life and characterized their playing as "excessive". They identified specific problems connected with excessive playing.

Irritability/Distress

Social life neglect

Disruption of relationships

Sleep lost

University or job failure

Loss of interest in other activities

Economic burden

Extract: "I wasn't interested in anything else but my character. I didn't want to sleep or eat, I was anxious feeling that all the others were connected, and the plot was continuing"

Extract: "My friends were the other characters and that was enough"

Extract: "Everyone was against me. My mother, my sister, my friends.... But I didn't mind. I had a marvelous time!"

Extract: "I have decided to stop all that. It was very difficult, but my social life was ruined"

\section{Tabletop players}

The duration and the timing of the game were highlighted. Players have identified the issue of time limit. In order for a play to be fulfilled you have to dedicate at least 5-6 hours in one afternoon every week. You couldn't' be absent because you would lose the plot.

Extract: "My team gathered every Saturday from 5.00am to $12.00 \mathrm{pm}$. At the end I had many problems with my girlfriend spending all Saturdays with my friends"

Extract: "Unfortunately I had to stop playing because I had a busy week and only one afternoon to rest. The master of the game refused for me to participate whenever I could...."

\section{Theme: Positive effects}

\section{Online players}

\section{Interesting}

Players pointed out that internet games are extremely interesting. The game provides you with the satisfaction of being a part of community: "RPG's community".

\section{Social support/integration}

The game gives you a sense of belonging with other players who speaks the "same language, "has the same enthusiasm", "has the same problems".

Extract: "you have so many funs playing games.... I was looking forward to playing games..."
Additionally, a number of players indicated a sense of social support and social interaction between players.

Extract: "We are a team. We have the sense that we support each other"

Some players admitted that even though this is an online game "it is a social game after all because in most cases, you cooperate with others even if they are total strangers to you"

\section{Different personalities}

A player noticed that one of the positive things is the opportunity to explore different parts of the personality.

Extract: "Players take a role and use their imagination. They also cooperate sometimes for the same purpose"

\section{Escape from the reality and stress}

A player noticed that playing a game offered him a sense of freedom.

Extract: "I could be and do everything.... good, bad, kill people, stole things with no real-life consequences. That was very interesting!"

Extract: "When I was playing I was forgetting everything.... even my stressful thoughts!"

\section{Tabletop players}

All players summarized a number of positive effects deriving from pen and paper playing:

\section{Improved social interactions}

Extract: "Playing for me was an opportunity to gather with my friends. There is no meaning to sit in front of a screen"

Extract: “... with this game you learn how to become a team player"

\section{Long-lasting friendships}

Extract: "I will always remember my team with nostalgia and tenderness. We still talk to each other after all these years"

Extract: "there are no winners or losers in this game. We are all together..."

\section{Excitement}

Extract: "I was looking forward to the next session. I was so excited"

Feelings of satisfaction

Pleasure

Extract: "The best time ever! The best game!"

Impromptu acting

Extract: "We could have different personalities, cooperate, laugh, and quarrel.... everything..."

Critical thinking and problem solving

Extract: "We had to resolve situations, to find different solutions... you have to think quickly and react"

Theme: Possible causes for their behavior/possible explanations about addiction

\section{Online players}

In most cases players admitted that this possible "addiction" came unexpectedly. 
Extract: "One minute I started the game, and, in a few days, I found myself thinking of nothing else'

Extract: "the game was a time out for me at the beginning...but later was the main theme in my whole life"

One player said that he always preferred lonely games and this game offered him the opportunity to fulfill his inclination while remaining in contact with others in a no direct manner.

Extract: "I never liked team games. I was rather the lonely type. This game gave me the opportunity to be myself and the illusion that I was also part of a huge world"

And another added that "people say that gaming is a lonely activity, but I liked being alone"

Another player raised the issue of misuse. He mentioned that the game itself is very interesting, but the use of time spent, and control of time were the main problem.

Extract: "The length of time I was dedicating was the problem. It never seemed to be enough"

\section{Tabletop players}

All players admitted that there is no addictive nature in tabletop playing. They pointed out that they were waiting impatiently for the next gathering of the team but in a rather enthusiastic way.

Extract: "You cannot be addicted with such a game. Of course, our master was furious if it was not possible for someone to come but everything was part of the game"

Extract: "Every time that the game ended I wanted more and more.... I couldn't wait till next Friday!"

Extract: "The only addiction was that I was thinking about the game all week long"

\section{Theme: Future intentions/proposals}

\section{Online players}

Some players pointed out that they will not play again in the future because they feel that they cannot control the time spent. Other wished that there was a "mechanism to control the time and dedication" to the game, so they could play again.

Extract: "I wish I had the strength to limit the time spent in such a game. I would play again with all my heart"

\section{Tabletop players}

All participants said that are willing to play again pen and paper RPGs if they can find the time. Concerning the internet games, some of them mentioned that they will not play because of the fear to be addicted. A few admitted that they have already seen the games and would like to play some time.

Extract: "I have seen internet games, but I will not play. I am afraid that it will be impossible for me to stop playing!"

It is of notice that some players suggested tabletop game as therapeutic method for online player's addiction.

"If you persuade all online gamers to participate in tabletop game you will eliminate all addictive problems or problems of misuse'

\section{Discussion}

In order to investigate solely the effect of the game on player's lives we have tried to choose persons with no record in mental health or psychological problem in the time of the interview. A number of important factors appeared to emerge from the data that suggested that the different forms of the same type of games is an essential factor concerning addiction. The researcher has chosen only males because of two reasons; the first reason was that it was rather difficult to find a woman that had played tabletop RPG or online RPG. Additionally, previous studies have shown that the majority of role playing gamers are males. A study by Thornes et al. (2014) [9], concerning problematic internet users has demonstrated that $98 \%$ of the sample was male, $46 \%$ of those were playing massively multiplayer online role-playing games. The majority were players in their university life as undergraduate students [6].

\section{Games' characteristics}

Games' characteristics have been associated with players' views and attitudes. Massively Multiplayer Online Role-Playing Games (MMORPGs) are a very popular and enjoyable leisure activity. The game itself with the adventures, the different possibilities, the achievements and finally, the sense that you are escaping from the reality contributed in player's motivation towards the game [10]. All players identified that the game itself is extremely interesting, but in the case of online gaming, this notion contributed to an addictive tendency.

\section{Negative effect on players' lives}

Online players have identified a number of negative effects in the student period like irritability, distress, social life neglect, and disruption of relationships; sleep lost, university or job failure, loss of interest in other activities and economic burden. A previous study concerning the prevalence of IGD among internet users have identified more psychological distress among internet players while students [11]. A study about IGD and adolescent mental health found that there is a statistically significant association between IGD and male gender, a higher degree of adolescent antisocial behavior, anger control problems, emotional distress, self-esteem problems, and hyperactivity/inattention [3].

According to DSM-5 repetitive gaming leads to neglecting other activities. Eating or sleeping, academic performance or work is neglected in favor of a game which also leads to a tension in interpersonal relationships. Previous studies identified social neglect and work problems associated with MMPORPGs [6].

Time spent to the game was extremely important and mentioned by online gamers. Previous studies have shown that online playing gamers especially in MMORPGs tend to spend much more time playing than those players of non-MMORPGs [12,13]. The time that players spent playing games was associated with lower academic performance, a result consistent with previous research [14]. Late night play and the effort to synchronize with other players from all over the world in order to complete the mutual tasks of the game may have a negative effect on player's health status, like sleep problems $[15,16]$.

Tabletop players admitted that there are no negative consequences. Even though they have mentioned the long-time length per session, in most cases they noticed that time was not enough for such an interesting game. 


\section{Positive effects}

All players referred to the social aspect of the game. Even online players have identified that they were interested in relating with other players, a result consistent with previous study [10]. Online players reported a sense of satisfaction, social support and interaction with other players, derived from the game. Previous study has indicated that there is a connection between game engagement and in-game social support for medium time spent players [17]. Tabletop players demonstrated the social aspect of the game, players experience friendship, cooperation and communication with others.

All players identified the different roles and the formation of a character as a positive aspect. The possible positive effect of this "escape from self" that may alleviate stress and negativity was underlined by Kwon et al (2011) in a study about online gamers [18].

This distraction from real life and everyday roles has highlighted different aspects. Players have identified this aspect as beneficial, but research has shown that it may lead to even greater isolation and loneliness [19].

\section{Possible causes for their behavior/possible explanations about addiction}

This study was concentrated only on role-playing games. Previous studies identified that role-playing game users like MMORPG have showed significantly higher internet addiction scores than web board and sports game users $[20,21]$. We have asked players to give their own explanation about their behavior, given the fact that there is not yet a globally accepted instrument to screen patients as an effort to clarify players' points of view [9]. Additionally, there is no validated scale to determine internet addiction connected to MMORPGs [6]. Players identified social anxiety and a tendency to loneliness as possible factors, a result consistent with previous study [22]. It is important that a number of players could not explain their behavior which may identify a compulsive tendency in those players, to be examined [23].

Players in tabletop game need the presence of other players. Even though all players reported extreme enthusiasm for the fantasy games, it seems that the presence of the other members of the team eliminate the possibility of a problematic use or addiction in tabletop game. The team acts as an external control factor. It is of note, that tabletop players mentioned that they will not try to play online, for the fear of addiction.

\section{Future intentions/proposals}

It is possible that certain personality characteristics may contribute to the expression of an addictive behavior or the choice of the games' type. More research through lifespan, may clarify why certain individuals make a certain game choice and the causal link with individual tendencies. Additionally, research concerning a large number of tabletop players continuing as online players for a period of time, will confirm if there is a correlation between addictive tendencies and games' characteristics.

It was quite impressive that tabletop players proposed a therapeutic solution for internet misuse. They mentioned that online player's participation in a tabletop game will diminish or even make symptoms of addiction disappear. They noticed that the game itself will attract players and will provide them with an enjoyable alternative.

\section{Limitations and relevance for clinical practice}

In terms of clinical practice, augmenting our knowledge regarding the pathogenesis and maintenance of Internet and gaming addiction, in correlation with game's type, is essential for the development of specific and effective treatments. This study was based on player's views and recollections and it was impossible to delineate if there was a case of addiction between them, during the previous years. All players have stopped playing without external/therapeutic help, which may underline the fact that there is no proven addictive behavior.

\section{Conclusion and future directions}

In this study, the main research question referred to the game itself. All players recognized an "addictive dynamic" of the game [24]. Only 4 out of 18 players of internet games characterized their use of the game as "addiction". Time loss and difficulty breaking off, were the main problems. Online players identified both positive and negative effects upon their lives [25]. Tabletop players only referred to the length of time per session, as a problem. In this study, all players succeeded to cut back the game without external help. It is of notice that all players reported that they will not play again online. Future studies have to investigate in depth, the underlying factors affecting addiction given the fact that the game itself has an addictive dynamic when played online.

\section{Conflict of interest}

I am the only author and I don't have a conflict of interest to declare.

\section{References}

1. American Psychiatric Association (2013) Washington DC, VA: Diagnostic and Statistical Manual of Mental Disorders (DSM-5)

2. Wartberg L, Kriston L, Kammerl R (2017a) Associations of Social Support, Friends Only Known Through the Internet, and Health-Related Quality of Life with Interne Gaming Disorder in Adolescence Cyberpsychol Behav Soc Netw 20: 436-441. [Crossref]

3. Wartberg L, Kriston L, Thomasius R (2017b) Internet gaming disorder in early adolescence: Associations with parental and adolescent mental health. Eur Psychiatry 43: 14-18. [Crossref]

4. Kuss DJ, Lopez-Fernandez O (2016) Internet addiction and problematic Internet use: A systematic review of clinical research World J Psychiatry 6: 143-176. [Crossref]

5. Young K (2009) Understanding online gaming addiction and treatment issues for adolescents. The American Journal of Family Therapy 37: 355-372.

6. Achab S, Nicolier M, Mauny F, Monnin J, Trojak B, et al. (2011) Massively multiplaye online role-playing games: comparing characteristics of addict vs non-addict online recruited gamers in a French adult population. BMC Psychiatry 11: 144. [Crossref]

7. Ahn DH (2007) Korean policy on treatment and rehabilitation for adolescent's internet addiction. International Symposium on the Counselling and Treatment of Youth Internet Addictions; Seoul, Korea: National Youth Commission, 497.

8. Ko CH, Yen JY, Yen CF, Chen CS, Chen CC (2012) The association between Internet addiction and psychiatric disorder: a review of the literature. Eur Psychiatry 27: 1-8. [Crossref]

9. Thorens G, Achab S, Billieux J, Khazaal Y, Khan R, et al. (2014) Characteristics and treatment response of self-identified problematic Internet users in a behavioural addiction outpatient clinic. J Behav Addict 3: 78-81. [Crossref]

10. Fuster H, Carbonell X, Chamarro A, Oberst U (2013) Interaction with the game and motivation among players of massively multiplayer online role-playing games. Span $J$ Psychol 16: E43. [Crossref]

11. Subramaniam M, Chua BY, Abdin E, Pang S, Satghare P, et al. (2016) Prevalence and Correlates of Internet Gaming Problem among Internet Users: Results from an Internet Survey. Ann Acad Med Singapore 45: 174-183. [Crossref]

12. Ng BD, Wiemer-Hastings P (2005) Addiction to the internet and online gaming. Cyberpsychol Behav 8: 110-113. [Crossref]

13. Peters CS, Malesky LA (2008) Problematic usage among highly-engaged players of massively multiplayer online role-playing games. Cyberpsychol Behav 11: 481-484. [Crossref]

14. Kim JW, Han DH, Park DB, Min KJ, Na C, et al. (2010) The Relationships between Online Game Player Biogenetic Traits, Playing Time, and the Genre of the Game Being Played. Psychiatry Investig 7: 17-23. [Crossref] 
15. Lemola S, Brand S, Vogler N, Perkinson-Gloor N, Allemand M (2011) Habitual computer game playing at night is related to depressive symptoms. Personality and Individual Differences 51: 117-122.

16. Lam LT (2014) Internet gaming addiction, problematic use of the internet, and sleep problems: a systematic review. Curr Psychiatry Rep 16: 444. [Crossref]

17. Longman H, O'Connor E, Obst P (2009) The effect of social support derived from world of warcraft on negative psychological symptoms. Cyberpsychol Behav 12: 563566. [Crossref]

18. Kwon JH, Chung CS, Lee J (2011) The effects of escape from self and interpersonal relationship on the pathological use of internet games. Community Ment Health $J 47$ 113-121. [Crossref]

19. Holtz P, Appel M (2011) Internet use and video gaming predict problem behavior in early adolescence. $J$ Adolesc 34: 49-58. [Crossref]

20. Na E, Choi I, Lee TH, Lee H, Rho MJ, et al. (2017) The influence of game genre on Internet gaming disorder. $J$ Behav Addict [Crossref]
21. Lee MS, Ko YH, Song HS, Kwon KH, Lee HS, et al. (2007) Characteristics of Internet use in relation to game genre in Korean adolescents. Cyberpsychol Behav 10: 278-285. [Crossref]

22. Park JH, Han DH, Kim BN, Cheong JH, Lee YS (2016) Correlations among Social Anxiety, Self-Esteem, Impulsivity, and Game Genre in Patients with Problematic Online Game Playing. Psychiatry Investig 13: 297-304. [Crossref]

23. van Rooij AJ, Schoenmakers TM, van de Eijnden RJ, van de Mheen D (2010) Compulsive Internet use: the role of online gaming and other internet applications. $J$ Adolesc Health 47: 51-57. [Crossref]

24. Grüsser SM, Thalemann R, Griffiths MD (2007) Excessive computer game playing: evidence for addiction and aggression? Cyberpsychol Behav 10: 290-292. [Crossref]

25. Lukavská K, Hrabec O, Chrz V (2016) The Role of Habits in Massive Multiplayer Online Role-Playing Game Usage: Predicting Excessive and Problematic Gaming Through Players' Sensitivity to Situational Cues. Cyberpsychol Behav Soc Netw 19: 277-282. [Crossref]

Copyright: (C2018 Koukia E. This is an open-access article distributed under the terms of the Creative Commons Attribution License, which permits unrestricted use, distribution, and reproduction in any medium, provided the original author and source are credited. 